\title{
¿Es la enfermedad periodontal un factor de riesgo para las enfermedades cardiovasculares? (II) Modelo biológico
}

\author{
CASTRO LARA J * \\ IBERO SAGASTIBELZA I * \\ BASCONES IMARTINEZ A **
}

Castro Lara J, Ibero Sagastibelza I, Bascones Martínez A. ¿Es la enfermedad periodontal un factor de riesgo para las enfermedades cardiovasculares? (II). Modelo biológico. Av Periodon Implantol. 2001; 13, 3: 33-44.

\section{RESUMEN}

Siguiendo con la primera parte analizaremos los distintos aspectos de la posible influencia de la enfermedad periodontal en la enfermedad cardiovascular con el fin de llegar a una serie de conclusiones.

\section{PALABRAS CLAVES}

Enfermedad periodontal, enfermedad cardiovascular, enfermedad cardiocoronaria, infección, inflamación, factores de riesgo.

\section{CUALIDADES QUE DEBE CUMPLIR UN FACTOR PARA CONSIDERARSE COMO RIESGO O CAUSALIDAD DE UNA ENFERMEDAD}

Un factor de riesgo puede definirse como aquel factor biológico, ambiental o conductual el cual, cuando aparece, incrementa directamente la probabilidad de desarrollar la enfermedad; y que cuando se elimina se reduce dicha probabilidad (1).

Para averiguar si se puede afirmar que un factor incrementa el riesgo de padecer una enfermedad desde la evidencia, es necesario que, analizando los estudios longitudinales existentes en la literatura, ver si se cumplen una serie de criterios propuestos por Bradford Hill (1). Dichos criterios son los siguientes:

- Que exista consistencia en la asociación entre el factor y la enfermedad. Un factor es más probable que sea causal si existen muchos estudios, con resultados similares. Además es especialmente positivo que se utilicen muestras con características diferentes, métodos y periodos de tiempo distintos.
- Fuerza en la asociación. Cuanto mayor sea el odds ratio y el riesgo relativo, mayor será la fuerza. La validez del estudio la da el que esté libre de error.

- Secuencia temporal adecuada. El factor potencial debe siempre preceder a la enfermedad. Los estudios transversales no permiten determinar este aspecto.

- Especificidad en la asociación. Con cuantas más enfermedades se haya relacionado un factor menos probable será su relación causal con otra enfermedad. Este criterio es muy relativo pues hay muchas enfermedades que siguen un modelo multifactorial y un factor puede producir diferentes enfermedades. Un ejemplo es el tabaco.

- Grado de exposición (efecto dosis-respuesta). Debe de existir un gradiente de tal manera que cuanto más intensa sea la aparición del factor mayor debe ser la incidencia de aparición de la enfermedad.

- Explicación biológica. Debe de existir un modelo coherente y basado en el conocimiento y evidencia

* Licenciado en Odontología. Alumno del Doctorado. Universidad Complutense.

** Catedrático de Medicina y Cirugía Bucofacial. Universidad Complutense. 
científica que explique la relación entre la aparición del factor y la aparición de la enfermedad.

- Por último, debe haber una evidencia experimental que confirme los hallazgos de estos estudios observacionales. Este criterio es fundamental para que exista evidencia de causalidad. Uno de los incovenientes de los estudios observacionales es que no se puede controlar otros factores de riesgo que puedan confundir y alterar los resultados y por lo tanto no pueda confirmar una relación entre la exposición y la enfermedad de causa-efecto, tan solo una relación de riesgo o de probabilidad.

En los estudios experimentales o ensayos clínicos se puede determinar relaciones causales pues se controlan las diferentes variables. Son mediante este tipo de estudios como se consigue el mayor grado de evidencia científica, por lo tanto siempre interesa averiguar si el factor es causal (es decir que siempre que aparece, aparece la enfermedad) más que de riesgo.

A continuación trataremos de aplicar estos criterios en los cinco estudios longitudinales mencionados en la $1^{a}$ parte de nuestro trabajo.

\section{I) Consistencia y fuerza en la asociación}

La consistencia viene dada por la serie de estudios comentados anteriormente en los cuales existen resultados similares. Además se han utilizado distintas medidas tanto para la exposición (EP) como para la respuesta (ECV). En todos estos estudios se han controlado otros factores de riesgo que pudieran confundir el resultado.

En cuanto a la fuerza de asociación decir que es moderada pues los odds ratio y los riesgos relativos van de 1.2 a 2.8 (Cuadro 1 ).

\begin{tabular}{|lcc|}
\hline Estudio & Exposición & Medición \\
\hline Matrila y col (1995) & Indice Dent. Total & $R R=1.2$ \\
De Stefano y col (1993) & Indice Period. & $R R=1.2$ \\
Joshipura y col (1996) & Perdida dent. Con Perio. & $R R=1.7$ \\
Beck y col (1996) & Cohorte & OR= 1.5, 1.9,2.8 \\
Genco y col (1997) & Nivel óseo & OR $=2.7$ \\
\hline
\end{tabular}

Cuadro 1. Resumen con los Odds Ratio (OR) y los Riesgos relativas (RR).

\section{II) Secuencia temporal}

En cuatro de los cinco estudios se parte de sujetos sin patología cardiovascular previa y con patología oral salvo en el estudio de Mattila y col. (1995) en donde ya parten con sujetos con patología coronaria. Por lo tanto en este estudio no se cumple este criterio.

\section{III) Especificidad temporal}

La especificidad de la asociación entre las condiciones orales y las enfermedades cardiacas no esta clara en este momento. En todos los estudios las asociaciones positivas entre ambas se ha realizado ajustando para los factores de riesgo cardiovascular clásicos de tal manera que se evita posibles confusiones, lo cual es el aspecto favorable de estos estudios. Sin embargo, la EP se ha relacionado con otras enfermedades sistémicas como partos prematuros e incluso relacionados con toda causa de muerte. Este criterio no es muy significativo pues factores como el alcohol o el tabaco se relacionan con varias enfermedades y por lo tanto debe considerarse más otros criterios.

\section{IV) Efecto dosis-respuesta}

En el único estudio de los cinco en el que existe un "gradiente biológico" es el de Beck y col. en el cual se observó que cuanto mayor era la pérdida ósea mayor era el riesgo de ECV. Por lo tanto este criterio no es valorado por los diferentes autores.

\section{V) Evidencia experimental}

Solo existe un estudio experimental en animales de Hertzberg y col. (1992) (2), el cual consistía en inocular en conejos Streptococcus sanguis en cantidades grandes. Observaron como al poco tiempo se producía alteraciones cardiacas y pulmonares importantes. Respecto a este criterio se hecha de menos más ensayos clínicos aunque sean en animales pues se entiende que por problemas éticos es difícil la experimentación en humanos.

\section{VI) Modelo biológico}

En principio, sorprende que dos enfermedades tan distintas en cuanto a la clínica, diagnóstico, tratamiento y pronóstico como son la EP y la ECV puedan tener algo en común como se ha demostrado en la serie de estudios epidemiológicos que hemos comentado anteriormente.

Cuando se quiere establecer una relación causal basada en la evidencia entre un factor de exposición y la enfermedad, es necesario que se establezcan un modelo o explicación biológica que permita entender cómo se relacionan dos procesos distintos. Naturalmente cuanto más se base dicho modelo o explicación biológica en un conocimiento científico, evidente, actual y aceptado universalmente, mayor será el grado de asociación entre el factor de exposición y la enfermedad.

Para ello nos tenemos que basar, no en los factores de riesgo comunes para ambas enfermedades (tabaco, 
nivel socioeconómico, estrés, etc.) porque no es suficiente para explicar la asociación de las dos patologías, sino en el otro aspecto en el que coinciden ambas enfermedades, es decir, en la etiopatogenia, en la cual se puede observar que existen una serie de cambios patológicos que podrían relacionar la ECV y los procesos infecciosos (entre ellos la EP).

Un punto muy importante que hay que tener siempre en cuenta en este tema es que la periodontitis es una respuesta inflamatoria crónica resultante a unos invasores gram - anaerobios que contienen principalmente lipopolisacáridos (endotoxinas) con alta capacidad de patogenicidad, de tal manera que las bolsas periodontales se podrían transformar en una fuente crónica de tipo endocrino de citoquinas y mediadores lipídicos potencialmente nocivos (3) que son liberados al organismo.

La manera en la que las infecciones bucales y concretamente la EP puede contribuir a la formación de las placas de ateroma se basa fundamentalmente en diferentes posibles mecanismos los cuales puede actuar de manera independiente o concurrir varios de ellos: a) efectos directos de los agentes infecciosos sobre el endotelio y los cambios serológicos producidos como consecuencia de la misma. b) la actuación en la formación de los ateromas del sistema monocito/macrófago y los mediadores inflamatorios que se liberan en la respuesta inmunólogica a nivel de las bolsas. c) predisposición genética común a la enfermedad periodontal y a la arterioesclerosis. d) el papel de la pérdida dentaria.

Estos aspectos los iremos desarrollando a continuación.

\section{A) El papel de las bacteriemias y los cambios sero- lógicos secundarios a las mismas.}

Como vimos en la introducción según la literatura existente los procesos infecciosos comunes podría estar relacionado con las ECV. La cuestión sobre si la infección puede predisponer a que se forme aterosclerosis está aun sin responder pero se ha considerado que ciertos virus y bacterias juegan un papel directo o indirecto en la iniciación del desarrollo de las placas de ateroma.

Dentro de este primer apartado debemos de distinguir tres puntos distintos: a.l- la acción directa de los agentes infecciosos sobre las células endoteliales dañando a las mismas. a.2- los cambios serólogicos que se producen debido a la bacteriemia subsecuente. a.3- la acción de los endotoxinas o lipopolisacáridos cuando pasan al torrente circulatorio.

Con respecto al primer punto comenzaremos por los virus y concretamente por los citomegalovirus cuyo efecto aterogénico parece estar en discusión. El Citomegalovirus podría presentar cierta afinidad por las células endoteliales y en concreto por las placas de ateroma donde pueden ser detectados por técnicas de hibridación in situ de mRNA. Similarmente, inclusiones del Herpes Virus y mRNA Herpes han sido detectados en las células de la capa íntima de las arterias y en las placas de ateroma, donde podrían causar acumulación de LDL (4).

Con respecto a las bacterias hablaremos sobre la Chlamydia pneumoniae, bacteria gram-negativa intracelular que pude sobrevivir durante años en los macrófagos. Saiky y col. (5) encontraron que los niveles altos de anticuerpos contra esta bacteria estaban asociados con la enfermedad crónica coronaria y el infarto agudo de miocardio.

La Candida albicans recientemente se ha relacionado con la inducción in vitro de citoquinas proinflammatorias y moleculas adhesivas a las células endoteliales. Estas dos características patológicas están relacionadas con la formación de placas de ateroma y contribuyen en el reclutamiento de leucocitos debajo de la intima. Por ello las bacteriemias de Candida podría contribuir a la ECV (4).

La EP podría considerarse igual que otro proceso infeccioso crónico. Los dientes son las únicas superficies no descamativas en el cuerpo de modo que podrían acumularse unos niveles de bacterias de hasta $10^{9}$ sobre un único molar. El tamaño actual de esta carga bacteriana dependería del flujo de saliva, las fuerzas de cizallamiento de masticar diferentes alimentos, la biodisponibilidad de nutrientes de la dieta y los hábitos de higiene oral del individuo. Entre estos, la higiene oral sería la variable más importante y una higiene oral deficiente podría ser responsable de un aumento de 2 a 10 veces en la carga bacteriana sobre los dientes. Dos ecosistemas microbianos distintos coexisten sobre los dientes, formando comunidades de placa supragingival y subgingival (6).

Muchas especies facultativas gram positivos de la placa supragingival podrían superar la barrera física, defensiva y la elevada $\mathrm{pO}_{2}$ y el potencial positivo oxidación-reducción del tejido hospedador, es decir la barrera eléctrica. Si no son eliminados rápidamente por los fagocitos tisulares a través de los vasos del tejido conectivo gingival tienen acceso a la circulación general, proporcionando unas posibilidades muy elevadas de intercambio de productos tóxicos bacterianos entre la bolsa periodontal y el sistema circulatorio. Esto es probablemente la razón por la cual encontramos invariablemente especies facultativas en las válvulas cardíacas infectadas y prótesis articulares (6). 


\section{AVANCES}

Volumen 13 - No 3 - Diciembre 2001

Pero más que la placa supragingival son los organismos de la placa subgingival los que tienen un mayor acceso al hospedador, especialmente cuando existe enfermedad periodontal ya que pueden acceder al tejido conectivo sanguíneo a través del epitelio ulcerado de la bolsa periodontal. La superficie relativamente grande de las bolsas periodontales combinadas indica que es probable que más anaerobios gram negativos que contienen endotoxinas entren en el tejido conectivo subyacente que los organismo gram positivos facultativos. No obstante, debido a la elevada $\mathrm{pO}_{2}$ y al bajo potencial de oxidación-reducción de estos tejidos, así como sus péptidos antimicrobianos conocidos como defensinas, normalmente están almacenados y se destruyen en el interior y las células bacterianas viables raramente aparecen en la corriente sanguínea, pero sí los restos celulares y los lipopolisacáridos que son muy nocivos (6).

Estas bacteriemias van a ser, como es obvio, proporcionales a la intensidad y duración de la enfermedad periodontal y al grado de higiene oral del individuo. (6). También se ha comprobado que después de procedimientos dentales rutinarios como el cepillado dental se produce un tránsito de bacterias al torrente sanguíneo (6). De esta manera se crea un estado crónico de intercambio de bacterias y sus productos, que no es apreciable por el paciente ni por el médico (bacteriemia asintomática) pudiéndose ocasionar un daño orgánico a distancia en determinadas circunstancias.

Hay tres aspectos que sugieren cierta evidencia en que las bacterias periodontales podrían tener un efecto directo en la formación del ateroma. El primero de ellos viene de estudios en los cuales se han encontrado Porphyromonas gingivalis en ateromas de carótida y arterias coronarias (8)(9). En segundo lugar tenemos los hallazgos de Deshpande y col. (10) quienes demostraron in vitro que la $P$. gingivalis puede invadir y podría proliferar in las células endoteliales. El tercer aspecto de evidencia viene de los estudios de Herzberg y Meyer (11) mostrando que la $P$ gingivalis es capaz de inducir agregación de plaquetas y por lo tanto la formación de trombos. Otro posible mecanismo incluye la producción de proteasas por $P$. gingivalis u otros patógenos periodontales, los cuales podrían contribuir al remodelamiento de la matriz extracelular de las placas ateromatosas. En contra a todo esto hay que comentar que estas evidencias hasta el momento se basa in vitro o preliminar. Sin embargo, es razonable postular que organismos que infectan placas de ateroma podrían contribuir a su formación.

A continuación se desarrollará el segundo de los puntos de este primer bloque, es decir, en como puede contribuir los cambios serológicos debidos a la bac-

\section{Aspectos de la infección relacionados con la ECV}

- Niveles elevados de la serie blanca sanguínea.

Incremento de los niveles de fibrinógeno.

Respuesta del hospedador a las proteínas heat shock.

Proteína asociada a la agresión plaquetaria.

teriemias en los fenómenos de trombosis. La respuesta de defensa por parte del hospedador a la entrada de gérmenes supone una serie de cambios en sangre, como elevadas concentraciones de anticuerpos a estas especies (7) y posiblemente niveles elevados de células sanguíneas de la serie blanca. Esta situación no pasa inadvertida para el organismo, pudiendo generar una respuesta inmune superior a lo esperado. Baste como ejemplo saber que la leucotoxina del Actinobacillus actinomycetemcomitans provoca una respuesta de anticuerpos con unos niveles séricos similares a los que se pueden detectar en algunas enfermedades sistémicas diseminadas, como la sífilis terciaria (6). Kweider y cols. (12) demostraron que los pacientes periodontales que tenían niveles significativamente más elevados de placa supragingival que los controles periodontalmente sanos, tenían así mismo niveles significativamente más altos de células sanguíneas de la serie blanca que los controles. Como se ha demostrado (13), el tener periódicamente unos niveles elevados de células sanguíneas de la serie blanca, como ocurre en estos procesos infecciosos crónicos, son un factor de riesgo independiente para las enfermedades cardiovasculares debido a que el mayor número de células en la sangre supone un aumento de la viscosidad y una disminución de la velocidad de circulación y por lo tanto un incremento de la probabilidad de formación de trombos y acúmulo de grasas en las arterias. Así podemos concluir que es posible que una mala higiene oral y la enfermedad periodontal, al provocar una respuesta de los leucocitos, puedan predisponer a una enfermedad cardiovascular por esa vía.

Analizando las infecciones por C. pneumoniae y Helicobacter pylori se ha observado que se produce un incremento de los niveles de fibrinógeno en plasma (4). Lowe observó que los pacientes periodontales tenían un nivel sanguíneo de fibrinógeno significativamente mayor que los pacientes sanos. Los niveles altos de fibrinógeno predisponen a una enfermedad cardiaca futura debido a que favorecen el estado de hipercoagulación de los pacientes y la viscosidad de la sangre, predisponiendo a los pacientes a la ECV (14).

Otro aspecto que se ha empezado a considerar recientemente para explicar la asociación entre los procesos infecciosos y los riesgos cardiovasculares son la respuesta del hospedador a las proteínas heat 
shock Hsp65 (15). Las proteínas heat shock son importante para el mantenimiento de una función celular normal y pueden tener funciones adicionales como factores de virulencia para muchas especies bacterianas. En estudios animales (16) se ha demostrado que la inmunización de conejos con Hsp65 bacteriano inducía lesiones ateroescleróticas.

Otro estudio clínico sobre este tema fue el que se realizó en Austria (15) en el cual se concluyó que existía una asociación significativa entre los niveles séricos de anticuerpos al Hsp65 y la presencia de enfermedad cardiovascular. El modelo de enfermedad que se propuso para explicar los resultados clínicos fue que la infección bacteriana estimula la respuesta del hospedador al Hsp65 que es un antígeno inmunodominante fundamental de muchas especies bacterianas. Debido a la conservación evolutiva considerable de las proteínas stress, una de estas proteínas notablemente similar se expresa en la capa íntima del tejido cardiaco a las injurias mecánicas que sufre (como el estrés hemodinámico). La hipótesis que se plantea es que la interacción entre la Hsp65 expresada y la respuesta inmune inducida por la infección bacteriana sea responsable del inicio de las lesiones iniciales de ateroesclerosis (esto es lo que se conoce como una reacción cruzada)(16). Así, esto puede representar un mecanismo autoinmune inducido por infección bacteriana. Esto parece ser específico del Hsp65 ya que no se conocen más correlaciones para ningún anticuerpo autoinmune habitual (anti-colágeno, antinuclear, etc.). Además esta relación es demostrable únicamente en la población anciana y se ha propuesto que las concentraciones de anticuerpo Hsp65 podrían servir como prueba predictiva de riesgo cardiovascular en persona mayores. La deficiencia que se ha señalado a esta hipótesis es la identificación de la fuente de la infección bacteriana crónica, aunque Loesche y col. (6) plantean como hipótesis que la salud oral deficiente contribuye a la bacteriemia crónica y mantiene la estimulación de niveles elevados de Hsp65 en sujetos con elevado riesgo cardiovascular.

También se describe en la literatura la Hsp60, la cual es producida por el Bacterioides forsythus y la P. gingivalis, tiene un $60 \%$ de homología con las proteínas heat-shock del endotelio dañado y de las placas ateromatosas de tal manera que es posible que anticuerpos contra la Hsp60 de las bacterias periodontales (está demostrado la existencia de anticuerpos contras las Hsp en pacientes periodontales) provoquen una reacción cruzada contra dichas otras proteínas heatshock del endotelio lesionado (17).

Pero se necesitan más estudios sobre la reacción cruzada autoinmune de las proténas heat shock bacterianas y las proteínas heat schock expresadas en el tejido hospedador, especialmente si éstas se encuentran en el recubrimiento de los vasos sanguíneos y así conocer si la bacteriemia asintomática supone un riesgo para la ECV.

Otro punto a considerar es el papel que podría desempeñar la proteína asociada a la agregación plaquetaria (paap) en los fenómenos tromboembólicos. En este sentido, uno de los organismos que se ha estudiado ha sido el Streptococcus sanguis, que es una bacteria que participa en el inicio de la formación de la placa bacteriana colonizando los dientes y que ejerce un efecto protector en sujetos dentados. Pero cuando consigue acceder a la circulación sanguínea puede ser patógeno en determinadas circunstancias, de ahí su nombre, porque a menudo se aísla a partir del torrente sanguíneo y se le asocia con endocarditis subaguda.

Desde hace años se conoce su influencia negativa en el metabolismo plaquetario y con ello el aumento de la agregación plaquetaria. Herzberg y cols. (18) realizaron estudios para conocer la actividad trombogénica del S. sanguis. El experimento consistía en inocular en cantidades grandes en sangre de conejos cepas del S. sanguis. A los 30 segundos de la inoculación se produjo cambios en el electrocardiograma así como alteraciones en la presión sanguínea, contractilidad cardiaca e índice cardíaco (estos cambios son consistentes con el infarto de miocardio). Según los autores ciertas cepas de $S$. sanguis se adhieren de un modo directo y selectivo a las plaquetas humanas y en el plasma les inducen a agregarse ocasionando las alteraciones pulmonares y cardiacas. La expresión de la paap sobre la superficie celular parecía ser el factor de virulencia.

Erickson y cols. (19) han identificado un péptido heptámero de la paap que representa el dominio mínimo de interacción con las plaquetas y se ha demostrado que los anticuerpos dirigidos contra la paap impide el efecto trombogénico de la bacteria.

Pero la paap no es exclusiva del S. sanguis porque recientemente se ha encontrado también en la Porphyromona gingivalis que como es conocido es uno de los patógenos fundamentales de la enfermedad periodontal.

Pero estas no solo podrían interaccionar con las plaquetas de un modo directo sino que se postula que la capacidad trombogénicas de estas bacterias no sólo sería por una interacción directa con las plaquetas sino también de modo indirecto por una respuesta autoinmune ya que la paap comparte homología con una conocida familia de proteínas heat shock.

Según lo comentado hasta ahora se podría pensar que una bacteriemia subclínica crónica o aguda de origen 
dental (la cual es más frecuente de lo se cree), con microorganismos trombogénicos pueda contribuir a diferentes trastornos cardiovasculares.

Serían necesarios más estudios para conocer más exactamente la actuación de la paap y si el paso de ciertas bacterias debido a una higiene oral deficiente contribuye al riesgo de este tipo de enfermedades.

Y el tercer y último punto de este primer bloque como se dividió al principio es el papel de las endotoxinas. Como hemos dicho antes las bacteriemias son frecuentes incluso en procesos tan simples como el cepillado dental en pacientes periodontales. Normalmente suele haber un paso de LPS los cuales raramente van libres por el plasma sino unidos a la membrana de las células de Langerhans procedentes del epitelio o bien pasan directamente al torrente circulatorio donde pueden o inactivarse por acción de la albúmina, lactoferrina o transferrina o bien unirse a la proteína de unión a LPS (PUL) y así forman un complejo que pueden ir activando a otras células al unirse a receptores $\mathrm{CD}_{14}$ tanto solubles como de membrana. Este complejo LPS-PUL antes de unirse a ningún receptor puede inactivarse por las lipoproteinas LDL. Cuando se une el complejo a los receptores $\mathrm{CD}_{14}$ de las membranas de los monocitos, macrófagos o de las células endoteliales se activan y se favorece la formación de la placa de ateroma (expresión de moléculas de adhesión a endotelio, citoquinas y factores quimiotácticos, activación de las células del músculo liso, incremento del fibrinógeno y de la cantidad de células de la serie blanca) (4).

Si el complejo LPS-PUL se une a un receptor $\mathrm{CD}_{14}$ soluble se forma un agregado que puede originar una lesión en algún punto de la circulación que puede originar la formación del ateroma, sobre todo en aquellos lugares de mayor turbulencia hemostática lo que explicaría la predilección de aparición en determinados lugares.

También los LPS y los dipéptidos murales pueden tener efectos directos sobre el endotelio promoviendo la lesión vascular (4).

B) Papel de los monocitos y de los mediadores químicos inflamatorios liberados en el proceso infeccioso en el desarrollo de las placas de ateroma.

Aunque lo anterior podría ser importante en la aparición y desarrollo de las placas de ateroma, actualmente se le da más importancia a las citoquinas y a los monocitos activados que se liberan y activan respectivamente en las bolsas periodontales u otros procesos infecciosos y que podrían pasar al sistema circulatorio participando a distancia en el desarrollo de las placas de ateroma. Estas citoquinas alcanzan altos niveles séricos y están asociadas con fiebre y pirexia (4).
Estimulan la expresión de moléculas de adhesión.

Activan monocitos/macrófagos.

† acúmulo de cel. espumosas al $\uparrow$ la permeabilidad

CE a monocitos y colesterol.

Estimulan la proliferación de las C. Musc. Lisas junto al PDGF.

La IL-1 hace que las plaquetas, monocitos y neutrófilos liberen FAP.

Inhibe la lipóproteina lipasa lipidemia.

Estimulan la producción del fibrinógeno.

Cuadro 2. Acción de las Citoquinas liberadas en la EP al torrente circulatorio (IL-1, IL-6 y TNF- $\alpha$ )

Es bien conocido que, como consecuencia de la agresión bacteriana en la enfermedad periodontal, se libera en la respuesta defensiva del hospedador una serie de mediadores bioquímicos o citoquinas, entre los que destacan la Interleuquina $1 \beta$ (IL-1 $\beta$ ), la Interleuquina 6 (IL-6), el factor de necrosis tumoral alfa (TNF- $\alpha$ ) o la prostaglandina $\mathrm{E}_{2}$ y que pasan al torrente circulatorio. Pero como vimos en el desarrollo de las placas de ateroma, estas citoquinas participan en la aparición de las mismas, lo que supone como vemos un punto de coincidencia entre ambas patologías. Y es que estas citoquinas, independientemente del efecto lesivo que producen en los tejidos periodontales, activan el sistema monocito/macrófago incrementa la permeabilidad vascular y, estimulan la expresión de moléculas de adhesión endoteliales para que los monocitos pasen a la íntima, y además, estas citoquinas asociadas a la acción del factor de crecimiento derivado de las plaquetas (PDGF) y -estimulan la proliferación de la musculatura lisa vascular, favoreciendo la formación de la placa de ateroma (Cuadro 2).

Los factores que activan las plaquetas son las fibras de colágeno de la íntima y perivascular, ADP y trombina (20). La agregación también es fomentada por el factor de activación plaquetaria (FAP), una citoquina liberada por neutrófilos y monocitos así como por otras plaquetas activadas. Concretamente la liberación de esta proteína por estas células se debe fundamentalmente por la acción de la Interleuquina-1 liberada por los monocitos, neutrófilos y plaquetas activados. Dicha citoquina (IL-1) tiene efectos sobre el SNC, efectos metabólicos, hematológicos y sobre la pared vascular. Dentro de estos últimos nos interesa, por tener alguna posible relación con los procesos de formación de las placas de ateroma (56), las siguientes acciones:

- Adherencia leucocitaria incrementada (favorece la trombosis). 
- Aumento de la síntesis de prostaglandinas.

- Elevación de liberación del factor de activación plaquetaria.

- Permeabilidad capilar incrementada (por lo tanto incremento del paso de colesterol y monocitos desde la luz del vaso a la íntima).

- Hipertensión (conocido agente etiológico de las placas de ateroma por su daño mecánico sobre las células endoteliales).

Además las citoquinas estimulan la producción de fibrinógeno, que como hemos visto un alto nivel en sangre del mismo supone el principal factor relacionado con un estado de hipercoagulabilidad (por el incremento de la viscosidad) y protrombótico (4).

La activación plaquetaria y consecuentemente su agregación también se puede deber al Tromboxano $\mathrm{A}_{2}$ (que es un mediador que aparece en la periodontitis) y al Factor Von Willebrand que como veremos más adelante puede aparecer en los procesos infecciosos liberado por las células endoteliales debido al daño que sufren por acción de los lipopolisacáridos bacterianos (también lo liberan plaquetas activados).

Todos estos cambios hematológicos parecen que pudieran relacionar las infecciones crónicas como la periodontitis y el desarrollo de las placas de ateroma pero que aún no se han estudiado.

Otro aspecto es el de la proteína C-reactiva, que es una proteína reactiva aguda liberada por el hígado en los procesos inflamatorios (como es en la periodontitis), y que se ha asociado cuando aparece en sangre en un alto grado como un indicador de riesgo de infarto de miocardio y accidentes cerebrovasculares futuros (21). Los niveles séricos de proteínas C-reactivas se correlacionan positivamente con el nivel sérico del fibrinógeno, con la cantidad de células sanguíneas de la serie blanca y con el colesterol LDL; sin embargo, los niveles de proteína C-reactiva podría simplemente ser un sobreproducto del proceso local de aterogénesis más que un factor causante. Wu y col. (1999)(17) han encontrado recientemente que la proteína C-reactiva y el fibrinógeno plasmático estaban relacionados con la enfermedad periodontal lo que avala esta hipótesis.

Las citoquinas proinflamatorias producidas por los monocitos (IL- $1 \beta$, IL-6, TNF- $\alpha$ ) inhiben las lipoproteinas lipasas (permite el paso de lipoproteinas desde la sangre a los tejidos) originando una lipidemia. Así la lipidemia es característica de los procesos infecciosos crónicos (22)

Otro aspecto importante es el papel que juega los monocitos en la relación de ambas enfermedades. Como se mencionó anteriormente, el paso de los monocitos activados desde el torrente hacia la pared vascular (mediante la unión a las moléculas de adhesión endoteliales ICAM y VCAM) supone un proceso patogénico crucial en el desarrollo de la placa de ateroma. Este proceso puede producirse por la agresión de los lipopolisacáridos bacterianos (LPS) u otros sobre el endotelio, el cual libera una serie de citoquinas (TNF- $\alpha$ o IL- 1 ) que a su vez activan a los monocitos para emigrar a la pared vascular. Estas células infiltrativas puede dar lugar a posteriores células cebadas al cargarse de cristales de colesterol (por acción de las mismas citoquinas) o bien desarrollan aún más el proceso liberando citoquinas (los monocitos liberan IL-8 que es un factor quimiotáctico para reclutar leucocitos en esa área) o inducir la expresión de moléculas de adhesión en la superficie del angiotelio. Posteriormente, otros mediadores derivados de los monocitos, tales como el factor transformador del crecimiento (TGF) y el factor de crecimiento derivado de plaquetas (PDGF), incrementa la proliferación de las fibras musculares lisas hacia la íntima, incrementando el grosor de la pared. Como vemos se establece un círculo vicioso en el cual los distintos procesos se favorecen entre sí con el objetivo de eliminar la causa que altera al endotelio.

Por otro lado los monocitos también ocupan un papel fundamental en la etiopatogenia de la enfermedad periodontal. Los monocitos responden a la presencia de los LPS procedentes de las bolsas con su activación y la secreción de citoquinas. Hoy en día se conoce que la liberación de citoquinas por parte de estas células va a depender de factores ambientales como las lipoproteínas de baja densidad (LDL) (23) y de factores genéticos.

Empezando por el primero de ellos diremos que la presencia de niveles altos en sangre de LDL (como puede ocurrir en las dietas ricas en grasas) estimula la liberación de IL- $1 \beta$ y TNF- $\alpha$ por parte de los monocitos de 3 a 5 veces mayor cantidad (por lo tanto se agravaría la EP y la ECV). De forma contraria, las lipoproteínas de alta densidad (HDL) suprimen esta secreción (24)

En segundo lugar decir que actualmente se tiene conocimiento de cómo la respuesta defensiva a los periodontopatógenos es muy variable de unos individuos a otros debido a las diferentes características genéticas, de tal manera que algunas personas responden con una reacción inflamatoria exagerada, caracterizada por la secreción por parte de sus monocitos de una alta cantidad de mediadores inflamatorios. Estos sujetos se han clasificado como fenotipos $\mathrm{Mq}^{+}$y descargan estas moléculas en concentraciones superiores a los sujetos normales (fenotipo $\mathrm{Mq}^{-}$). Esto individuos $\mathrm{Mq}^{+}$son capaces de secretar de 3 a 10 
veces más citoquinas (PG $E_{2}, \mathrm{IL}-1 \beta$, TNF- $\alpha$ ) que un sujeto normal. Estos mediadores citoquínicos participan activamente en la activación de los osteoclastos, macrófagos y demás procesos catabólicos, originando una destrucción periodontal. Esta demostrado que los pacientes con formas agresivas de EP (periodontitis de comienzo temprano, periodontitis refractaria y periodontitis asociada a diabetes mellitus insulinodependiente) poseen este fenotipo de monocitos hiperreactivos (27).

Estos monocitos circulantes al pasar por las bolsas periodontales que son áreas con una gran liberación de citoquinas, LPS bacterianos o actividad metaloproteinasa se activarían y al pasar de nuevo a la circulación, liberarían citoquinas (sobre todo en fenotipos $\mathrm{Mq}^{+}$) que podrían tener influencia sobre otras células circulantes o sobre el angiotelio a las que se podrían adherir, ocasionando ateromas en lugares a distancia, particularmente en áreas de turbulencias o donde la vascularización está ya dañada (4).

C) Predisposición genética común para la enfermedad periodontal y aterosclerosis.

Podrían existir mecanismos genéticos comunes los cuales explicarían la relación entre la enfermedad periodontal y la enfermedad cardiovascular. Dentro de este aspecto estaría la teoría de los macrófagos con fenotipo de hiperrespuesta inflamatoria que contribuiría a la susceptibilidad para la aterosclerosis.

\section{D) Perdida dentaria.}

Como se ha visto en los estudios epidemiológicos los individuos edéntulos o con pocos dientes en boca $(28,29,30,31)$ tenían un riesgo incluso mayor de enfermedad cardíaca coronaria y de muerte. En particular, los individuos jóvenes edéntulos (25-49 años) tenían un probabilidad 2.6 veces mayor de morir de cualquier causa que los individuos dentados con una edad comparable (30). Mientras que muchos factores potenciales de confusión podrían haber influido sobre este resultado, la mayoría como el tabaquismo, beber alcohol, ejercicio físico, el índice de masa corporal, la educación, entre otros, fueron tenidos en cuenta en el análisis, de modo que se demostró que ser desdentado era un factor de riesgo independiente de muerte por cualquier causa.

Las razones para esto serían complejas. Todos los acontecimientos patofisiológicos asociados con una infección e inflamación crónica serían aplicables a estos individuos hasta el momento de la pérdida de los dientes. La EP y las caries son dos motivos muy importantes de pérdida dentaria, por lo tanto se supone que estos individuos han estado sufriendo importante daño por estas infecciones sobre el sistema car- diovascular. Esto combinado con otros factores de riesgo relacionados con su estilo de vida explicarían la muerte temprana de estos individuos.

No obstante, en los individuos menos susceptibles, esto sería muy relativo pues si la pérdida dentaria se produce antes de que se produjese el daño a los tejidos cardiovasculares podrían sobrevivir hasta una edad avanzada, con la "tranquilidad" de que no va a sufrir ningún proceso infeccioso bucal que lesione sus arterias.

Pero esta ventaja del desdentado no es así pues aparecen unas nuevas situaciones que pueden favorecer el desarrollo de ECV y que explicaría los resultados de los estudios anteriores.

En primer lugar decir que como consecuencia de la pérdida dentaria se produce un cambio en los hábitos nutricionales (31), que consisten en una reducción de los alimentos ricos en fibra, fruta y/o carotenos (comestibles que requieren un mayor grado de trituración), y un aumento en la ingesta de una serie de alimentos blandos, con un gusto agradable, y que generalmente suelen ser alimentos ricos en grasas, hidratos de carbono y colesterol (flanes, dulces, etc). Todos estos cambios dietéticos conllevan un aumento del riesgo cardiovascular.

En el trabajo realizado por Joshipura y col (32) observaron que al obligar a tomar dietas ricas en fibras y zanahorias a los sujetos con menos de 10 dientes en boca, se producía una ligera reducción del riesgo relativo, sugiriendo que la dieta podría explicar una pequeña parte de la asociación en su estudio. También critican que en otros estudios no se incluya las variables dietéticas (fruta,vegetales, etc) para evaluarlas pues hoy en día se reconocen como factores de riesgo de las ECV y podría estar confundiendo y sesgando los resultados de aquellos trabajos sobre este tema.

Además las dietas ricas en ácidos grasos insaturados podrían proporcionan cantidades importantes de ácido araquidónico que constituye el principal fosfolípido de la membrana celular. Dicho ácido es liberado de la membrana por una lipasa $\mathrm{A}_{2}$ y posteriormente es oxidado por un ciclooxigenasa o por una lipooxigenasa dando como resultado la síntesis de tromboxanos, prostaglandinas y leucotrienos que son moléculas que tienen efectos importantes sobre la función de la fibra muscular, los fenómenos inflamatorios celulares, el metabolismo del colesterol, la agregación plaquetaria y la liberación de citoquinas (27).

Por otro lado podemos decir que en la decisión de extraerse un diente puede influir además del estado en el que se encuentra otros factores. Así los que deciden hacerlo por motivos económicos son los de 
mayor riesgo cardiovascular. Suele además coincidir que son los que menos aprecio tienen, no sólo por su boca, sino por su salud general y por tanto los que más fuman, menos ejercicio hacen y más dietas ricas en grasas consumen. Estas situaciones agravan la enfermedad coronaria y su patología bucal la cual incrementa a la primera. Como vemos se forma todo un círculo en el que todo se relaciona con todo debido a los factores comunes de riesgo de ambas enfermedades.

Y por último se podría considerar que aquellos pacientes que están preocupados por la estética de su pérdida dentaria por sus relaciones sociales, les supone un incremento de la ansiedad y del riesgo cardiovascular (32).

\section{DISCUSIÓN}

Nuestro objetivo y nuestra pregunta de trabajo al comenzar este artículo fueron el analizar los estudios realizados sobre el tema para ver si se podía afirmar, basándonos en la evidencia a partir de dichos estudios, de si la infección oral, y más específicamente la periodontitis, podría considerarse un elemento que favoreciese la aparición de aterosclerosis, dentro de un modelo en el cual también participan otra serie de factores.

Para ello, en primer lugar, vamos a responder a la pregunta de si la periodontitis se puede considerar un factor de riesgo y posteriormente se irá un poco más allá al intentar juzgar si entre la periodontitis y las ECV podría existir una relación causal.

Con respecto al primer punto decir que en la literatura nos hemos encontrado con cinco estudios longitudinales y ocho transversales. Como ya se dijo, los estudios observacionales longitudinales, ya sean de cohortes o de casos y controles, siempre tienen una mayor validez que los estudios transversales pues en estos últimos no se establece una secuencia temporal, es decir, no se puede saber si la exposición al factor fue antes de que apareciera la enfermedad, lo cual es fundamental, pues siempre el factor tanto causante como de riesgo deben aparecer antes de la enfermedad con la que se le relaciona. Los estudios transversales permiten hacer análisis de incidencia y prevalencia, pero es a través de los estudios observaciones longitudinales con los que vamos a estudiar más seriamente la relación entre la exposición y la enfermedad, aunque nunca vamos a tener una certeza absoluta (con estos estudios sólo se puede llegar a establecer relaciones de probabilidad) pues para llegar a contestar a nuestra hipótesis causa-efecto es necesario realizar ensayos experimentales en los que el investigador permite controlar todas aquellas variables que pudiera alterar el resultado. Volviendo al tema, tanto los análisis transversales como longitudinales han concluido con una asociación positiva entre el status oral (periodontitis, higiene oral, pérdida dentaria, otras infecciones, etc.) y la ECV. Pero nosotros consideramos que sólo cinco estudios longitudinales son quizá escasos para llegar a una conclusión definitiva, aunque en dichos trabajos se han manejado muestras muy grandes, variadas en cuanto a sus características y se han utilizado distintos parámetros para medir la EP y los procesos bucales (profundidad de sondaje, pérdida ósea, número de dientes en boca, etc.).

Los índices de odds ratio y de riesgo relativo permiten en los estudios de casos y controles y de cohortes respectivamente ver si existe una asociación positiva y la fuerza de ésta entre la exposición y la enfermedad. Cuando estos índices son mayores de 1 existe una relación y cuanto más alta sea más fuerte será la relación. Con respecto al tema que analizamos se ve que estos valores van de 1.2 a 2.8 , lo cual indica que sí existe una asociación pero con una fuerza moderada, lo que deja en duda si en estos resultados no han influido otra serie de variables que interaccionan con la enfermedad y en consecuencia altera los resultados. Estas variables serían aquellos otros factores de riesgo de las ECV como el colesterol, tabaco, diabetes, etc. (la aterosclerosis es una enfermedad multifactorial) que en la mayoría de los estudios se han controlado aunque podría destacar otras como las actitudes personales hacia la salud general y oral, el ejercicio físico o el estrés que se relacionan con ambas entidades y que no se han controlado pudiendo sesgar los resultados. Además el tabaco es un importante agente etiológico de ambas enfermedades en las que aparece en una gran incidencia y que nosotros consideramos que es muy difícil controlar.

Con respecto al modelo biológico planteado para explicar la relación entre ambas enfermedades parece estar basado en un conocimiento científico lógico aunque aún existan dudas que deben resolverse mediante más experimentación

y así confirmar lo hasta hoy supuesto (como es la vía LPS- $\mathrm{Mq}^{+}$).

Por todo ello, nosotros consideramos que la EP podría considerarse como un factor de riesgo para la aterosclerosis aunque esta afirmación debe tenerse en cuenta, hasta el día de hoy, con bastante precaución, pues necesitamos más estudios, sobre todo de carácter experimental, en los cuales se controlen todos las variables relacionadas la ECV y en los que exista una relación dosis-respuesta (tan sólo aparece en el estudio de Beck y col.). Por el contrario debemos decir que no existe suficiente evidencia para determinar una relación causal. 


\section{REPERCUSIONES EN ODONTOLOGÍA}

De confirmarse la influencia de los procesos infecciosos bucales en la salud general mediante futuras investigaciones, estaríamos ante un problema en el que la salud bucal y el papel de los dentistas adoptarían una dimensión más importante, de mayor responsabilidad (aunque también los médicos deberían tener un mayor conocimiento sobre las afecciones bucales y su tratamiento). La población tendría un mayor interés por tratarse la EP y por mantener una mejor higiene bucal (1).

Según los estudios vistos anteriormente, la extracción indiscriminada de dientes podría suponer aumentar al paciente el riesgo de que padezca una aterosclerosis. Por ello, el profesional debe tratar adecuadamente la infección dental, educar a sus pacientes y ser lo más conservador posible con las extracciones.

El beneficio de la salud dental en la reducción del riesgo de la ECV podría ser una motivación muy potente tanto en aquellos pacientes que tienen una adecuada actitud respecto a la salud bucal, como para cambiársela a aquellos en los que esta percepción esta disminuida mediante una adecuada información. Y por una adecuada información se entiende que ésta no debe ser alarmista, pues no sería muy ético asustar a la población general.

El tratamiento de la EP y el mejoramiento de las condiciones orales se incluirían necesariamente en los protocolos de tratamiento y profilaxis de aquellos individuos con enfermedad coronaria y de aquellos en los que por sus antecedentes familiares, estilo de vida, etc., los hace susceptibles de padecerla.

Si se confirma todos estos supuestos, es posible que se pudiera originar implicaciones legales derivadas de la misma. De tal modo que aquel profesional que no diagnostique y trate la EP de un paciente, el cual ha estado acudiendo al dentista con cierta frecuencia, y que además ha sufrido un problema cardiovascular, puede encontrarse en una situación de litigio.

\section{CONCLUSIONES}

1. En las dos últimas décadas ha surgido un interés creciente por la influencia que sobre la salud general tienen los procesos infecciosos de origen bucal, la falta de higiene oral y la pérdida dentaria.

2. En la literatura existen diferentes datos sobre la influencia que tienen los procesos infecciosos sobre la aterosclerosis.

3. En los distintos estudios transversales, longitudinales y experimentales sobre la influencia de las infec- ciones bucales (y concretamente la enfermedad periodontal) en los accidentes cardiovasculares los autores refieren una asociación positiva entre ambos procesos.

4. Hoy en día existen aún dudas sobre este tema. Al aplicar los criterios que debe seguir todo factor para considerarse de riesgo de una enfermedad, observamos a raíz de los estudios longitudinales existentes que la periodontitis puede considerarse un factor que incrementa la probabilidad de desarrollo de la aterosclerosis aunque no existe evidencia suficiente para concluir causalidad entre ambas (es decir que siempre que aparezca una aparezca la otra). Para ello se necesitan estudios experimentales que permitan conocer más exactamente si la periodontitis participa en la formación del ateroma y el mecanismo.

5. Se ha planteado un modelo biológico racional y coherente que permite que la asociación entre la periodontitis y la enfermedad cardiaca sea biológicamente posible. Dicho modelo se basa en aquellos aspectos en los que coincide la etiopatogenia de ambas enfermedades, concretamente la vía endotoxina-monocito $\mathrm{Mq}^{+}$. Ésta consiste en la liberación de citoquinas proinflamatorias procedentes de los monocitos que entran en contacto con las endotoxinas bacterianas procedentes de las bolsas periodontales, que junto con la activación de estas últimas células van a favorecer el desarrollo de las placas de ateroma. Dentro del papel de la respuesta inflamatoria del hospedador destacan aquellos sujetos con un fenotipo monocito $\mathrm{Mq}^{+}$, que son los de mayor susceptibilidad a padecer accidentes cardiovasculares, pues presentan monocitos hiperreactivos que liberan exageradamente citoquinas en comparación con los sujetos normales. Aún así, se necesitan más estudios para analizar más a fondo otros aspectos de este modelo.

6. De confirmarse los hallazgos anteriores, esto supondría un nuevo enfoque médico-legal al tratamiento y diagnóstico de la enfermedad periodontal.

\section{ABSTRACT}

Continuing with the firtst part we will analyze the differents aspects of the possible influence of the periodontal disease in the cardiovascular disease with the intention of obtain some conclusions.

\section{KEY WORDS}

Periodontal disease, cardiovascular disease, coronary heart disease, infection, inflammation, risk factors. 


\section{BIBLIOGRAFÍA}

1. Beck JD, Offenbacher S. Oral Health and systemic disease: periodontitis and cardiovascular disease. J Dent Educa. 1998; 62 (10): 859-70.

2. Joshipura KJ, Douglass CW, Willett WC. Possible Explanations for the tooth loss and cardiovascular disease relationship. J Periodontol. 1998; 3 (1):175-81.

3. Offenbacher S, Katz VL, Fertik GS, Collins JG, Boyd DL et col. Periodontal infection as a risk factor for preterm low birth weight. J Periodontol. 1996; 67: 1103-13.

4. Kinane DF. Periodontal diseases' Contributions to cardiovascular disease: An overview of potential Mechanisms. Ann Periodontol. 1998; 3 (1): 142-50.

5. Saikku P, Leinoen M, Mattila K. Serologic evidence of an association of a novel Chlamydia, TWAR, with chronic coronary heart disease and acute myocardial infaction. Lancet. 1998; 2: 983-6.

6. Loesche WJ, Lopatin DE. Interacciones entre la enfermedad periodontal, las enfermedades médicas y la inmunidad en los ancianos. Periodoncia. 1998; 8 (4): 227-60.

7. Ebersole JL, Taubman MA, Smith DJ, Socransky SS. Humoral inmune responses and diagnosis of periodontal disease. J Periodont Res. 1982; 17: 478-80.

8. Haraszthy VI, Zambon JJ, Trevisan M, y col. Identification of pathogens in atheromatous plaques. J Dent Res. 1998; 77: 273.

9. Chiu B, Viira E, Evans RT, Genco RJ. Detection of an odontopathogen: P. gingivalis in atherosclerotic plaques: an inmunehistochemical and in situ hybridazation study. Appl Immunohistochem Molec Morphol. 1999.

10. Deshpande RG, Kahn MB, Genco CA. Invasion of aortic and heart endothelial cells by $P$. gingivalis. Infect Immun. 1998; 66: 5337-43.

11. Herzberg MC, Meyer MW. Effects of oral flora on platelets: possible consequences in cardiovascular disease. J Periodontol. 1996; 67: 1138-42.

12. Kweider M, Lowe G. Dental disease, fibrinogen y white cell count, links with myocardial infarction?. Scot Med. 1993; 38: 73-4.

13. Gillum RF, Ingram DD, Makuc DM. White blood cell count, coronary heart disease and death: the NHANES I epidemilogic follow up study. Am Heart J. 1993; 125: 855-8.
14. Lowe GDO, Kweider J, Murray GD, Kinane D, McGowan DA. Fibrinogen and dental disease-a coronary risk factor. Fibrinogen-a new cardiovascular risk factor. Vienna: Balckwell-MZV. 1992: 201-4.

15. Qingbo X, Willeit J, Marosi M et col. Association of serum antibodies to heat-shock protein 65 with carotid atherosclerosis. Lancet. 1993; 341: 255-9.

16. Qingbo X, Kleindienst $\mathrm{R}$ et col. Increased expresion of heat shock protein 65 coincides with a population of infiltrating $\mathrm{T}$ lymphocytes in atherosclerotic lesions of rabbits specifically responding to heat shock protein 65. J Clin Invest. 1993; 21: 2693-702.

17. Wu T, Trevisan M, Genco RJ y col. An examination of the relation between periodontal health status and cardiovascular risk factors: serum total and HDL cholesterol, C-reactive protein, and plasma fibrinogen. Am J Epidemiol. 1999.

18. Syed SA, Loesche WJ. Bacteriology of human experimental gingivitis: effect of plaque age. Infect Inmunol. 1978; 21: 821-9.

19. Erickson PR, Herzberg MC. The streptococcus sanguis platelet aggregation-associated protein. Identification and characterization of the minimal platelet-interactive domain. J Biol Chem. 1993; 268: 1646-9.

20. Ganong WF. Fisiología Médica. Ed.Manual Moderno. 1992.

21. Ridker PM, Cushman M, Stampfer MJ, Tracey RP, Mennekins $\mathrm{CH}$. Inflammation, aspirin and the risk of cardiovascular disease in apparently healthy men. $\mathrm{N}$ Engl Med. 1997; 336: 973-9.

22. Beutler BA, Cerami A. Recobinant interleukin-1 supresses lipoprotein lipase activity 3t3-Ll cells. J Inmunolo. 1985; 135: 3969-71.

23. Marcus AJ, Hajar DR. Vascular transcellular signaling. J Lipid Res. 1993; 34: 2017-31.

24. Joshipura KJ, Rimm EB, Douglass CW. Trichopoulos D, Ascherio A, Willet WC. Poor oral health and coronary heart disease. J Den Res. 1996; 75: 1631-6.

25. Korman KS, Pankow J. Offenbacher S, Beck J. di Giovine F. Interleukin-l genotypes and the association between periodontitis and cardiovascular disease. J Periodontol Res. 1999; 34: 353-7.

26. Iacopino AM, Christopher WC. Pathophysilogical relationships between periodontitis and systemic disease: Recent concepts involving serum lipids. J Periodontol. 2000; 71: 1375-84. 


\section{AVANCES}

Volumen $13-\mathrm{N}^{\circ} 3$ - Diciembre 2001

27. Carasol M, Estany J, Alandez FJ, Herrera JI. Las enfermedades periodontales y su posible relación con la patología coronaria. Periodoncia. 1999; 9 (1): 59-68.

28. Joshipura KJ, Rimm EB, Douglass CW, Ascherio A, Willet WC. Poor oral health and coronary heart disease. J Dent Res. 1996; 75 (9): 1631-6.

29. Mattila K, Valle M, Nieminen M, Valtonen V. Dental infections and coronary atherosclerosis. Atherosclerosis. 1993; 103: 205-11.
30. Paunio K, Impivaara, Tiekso J. Missing teeth and ischaemic heart disease in men aged 45-64 years. Eur Heart J. 1993; 14 (Suppl); 54-6.

31. Grau AJ, Buggle F, Stegler C. Association between acute cerebrovascular ischemia and chronic and recurrent infection. Stroke. 1997; 28: 1724-9.

32. Joshipura KJ, Douglass CW, Willett WC. Possible Explanations for the tooth loss and cardiovascular disease relationship. J Periodontol. 1998; 3 (1): 175-81. 